\title{
Conceptual Issues in Acute and Transient Psychotic Disorders
}

\author{
Augusto C. Castagnini ${ }^{a} \quad$ German E. Berrios $^{b}$ \\ aSchool of Child Neuropsychiatry, University of Modena and Reggio Emilia, Modena, Italy; \\ ${ }^{b}$ Department of Psychiatry \& Robinson College, University of Cambridge, Cambridge, UK
}

\section{Keywords}

Classification · Diagnostic systems · Diagnostic and

Statistical Manual of Mental Disorders · Nosology •

Psychotic disorders

\begin{abstract}
Short-lived psychotic disorders as currently listed under "acute and transient psychotic disorder," ICD-11 Classification of Mental, Behavioural, and Neurodevelopmental Disorders, and "brief psychotic disorder," Diagnostic and Statistical Manual of Mental Disorders (DSM-5), constitute a point of divergence in the classification of psychotic disorders between the 2 diagnostic systems, which reveals the lack of knowledge about these conditions. Whether this is due to conceptual shortcomings inherent to the categories themselves and which spill over onto research or reflects a mismatch between the diagnostic criteria used and research techniques needs clarification. This study aimed to examine conceptual issues involved in the development of the above categories and shows that little continuity exists between earlier nosological concepts such as bouffée délirante, cycloid psychosis, and reactive psychosis and modern descriptive categories used to classify short-lived psychotic disorders. It seems likely that shortcomings in terms of symptom completeness, specificity, and heterogeneity, in addition to changes in definition and diagnostic criteria in successive
\end{abstract}

DSM and ICD versions, have hampered empirical research, making it difficult to enhance the understanding of these conditions and achieve a closer concordance between the 2 classificatory systems.

(c) 2021 S. Karger AG, Basel

\section{Introduction}

The dichotomous Kraepelinian [1] classification of dementia praecox (later renamed schizophrenia) and manic-depressive psychosis (i.e., bipolar disorder) has, since its inception in the late nineteenth century, caused difficulties for the identification and understanding of "intermediate" categories that do not fit into either of its polarities and has obfuscated Kurt Schneider's [2] question of "whether (in such cases) a psychic reaction or a psychosis is present" (p. 47). Several of these intermediate conditions such as bouffée délirante [3], cycloid psychosis $[4,5]$, and reactive psychosis $[6,7]$ were subsumed under "acute and transient psychotic disorders" (ATPDs) by the ICD-10 Classification of Mental and Behavioural Disorders (ICD-10) [8], while the American Psychiatric Association's Diagnostic and Statistical Manual of Mental Disorders (DSM) has, since its fourth edition, listed "brief psychotic disorder" (BPD), whose description and diagnostic criteria are almost unchanged in DSM-5 [9].

Correspondence to:

Augusto Cesare Castagnini, augusto.castagnini@unimore.it

karger@karger.com

(c) 2021 S. Karger AG, Basel

Karger $\stackrel{\text { ' }}{5}$ 
Although current diagnostic categories are essential for international communication and research, the lack of neurobiological findings and poor predictive power have called into question the validity of short-lived psychotic disorders [10], and it has not helped that empirical data have seldom been efficiently studied $[11,12]$. The ATPD category has undergone significant changes in the forthcoming ICD-11 revision [13], but it remains a case of divergence within the listing of psychotic disorders with DSM-5 [14].

Moreover, international clinical practice suggests that patients suffering from short-lived forms of psychosis are regularly met in low- and middle-income countries, where they are more likely to be associated with environmental risk factors than in high-income countries [15], and hence it may be time to consider whether the above difficulties (a) result from conceptual shortcomings affecting the categories themselves and which spill over onto empirical research or (b) reflect a mismatch between the diagnostic criteria employed and research techniques $[16,17]$. It is the aim of this study to examine conceptual issues involved in the development of these categories and raise awareness of how they have affected clinical practice and research.

\section{Terminology and Definitions}

To avoid assumptions about aetiology and symptom patterns, the ICD-10 ATPD category listed clinical syndromes with polymorphic, schizophrenic, and predominantly delusional symptoms characterized by acute onset within 2 weeks; complete remission within 1 or 3 months to set them apart from schizophrenia and persistent delusional disorder, which have at least 1- or 3-month duration, respectively; and association (or not) with "acute stress," defined as events stressful to most people such as bereavement and unexpected loss of partner or job occurring $<2$ weeks before the onset of symptoms [8]. Since the attempt by ICD-10 to incorporate different clinical conditions under ATPDs produced controversial results [1012], the ICD-11 [13] has restricted this category to "acute polymorphic psychotic disorder" (named "acute and transient psychotic disorder"); yet, the remaining subtypes featuring schizophrenic or predominantly delusional symptoms have been assimilated into other classes of the renamed section "schizophrenia and other primary psychotic disorders" [14]. The defining features of this category are similar to those currently in use for polymorphic ATPD and include (a) acute onset within 2 weeks without prodromal symptoms; (b) delusions, hallucinations, thought disorganization, perplexity or confusion, catatonia-like symptoms, disturbances of affect, and mood shifting daily or even faster; and (c) duration shorter than 3 months, while neither association with stress nor reference to bouffée délirante and cycloid psychosis is mentioned [13, 14]. Differential diagnosis of polymorphic ATPD involves schizophrenia and other primary psychotic disorders, substance-induced psychosis, and psychotic disorders secondary to medical conditions (Table 1).

The most similar category in DSM-5 [9] is BPD, but it differs from ATPD in that polymorphic symptoms are not mentioned, and its clinical profile includes delusions, hallucinations, disorganized speech, and grossly disorganized or catatonic behaviour lasting $<1$ month, and the period of onset is not specified [12]. In addition, schizophreniform disorder is a provisional category for cases with schizophrenic symptoms and duration intermediate between BPD and schizophrenia, which in turn requires at least a 6-month course and social/occupational dysfunction. One last minor point, DSM-5 listed "Attenuated psychosis syndrome" under "conditions for further study," but no category for people at high risk of psychosis will appear in ICD-11 [14].

These points of divergence are all the more striking, since ICD-11 has moved a step closer to a dimensional classification of psychotic disorders by reducing the role of Schneiderian first rank symptoms (FRS), replacing the different subtypes of schizophrenia (i.e., paranoid, catatonic, and hebephrenic) with psychopathological domains, and introducing additional codes for course specifiers in keeping with DSM-5 [14].

\section{Early Views}

Bouffée Délirante

The French concept of bouffée délirante was developed by Magnan and followers (Legrain and Saury) [3], who distinguished délire d'emblée (primaire, multiple, and polymorphe) from more stable and uniform delusional states (délire chronique à évolution systématique) pointing out its hereditary nature (bouffée délirante polymorphe des dégénérés) under the aegis of the theory of "degeneration." Since the early twentieth century, the theory of degeneration lost ground, and other types of acute psychosis set apart from schizophrenia and chronic delusional disorders were described such as la psychose imaginative (essentielle) aiguë [18], la psychose délirante dégénérative aiguë [19], and les états interprétatifs aigus curables [20].

Bouffée délirante then found its way into descriptions of psychoses délirantes aiguës, characterized by an inter- 
Table 1. Brief outline of ICD-11 ATPD and DSM-5 BPD

\begin{tabular}{|c|c|c|}
\hline & ICD-11 ATPD & DSM-5 BPD \\
\hline Onset & Acute $\leq 2$ weeks $^{1}$ & No time specified \\
\hline Symptoms & $\begin{array}{l}\text { Delusions, hallucinations, thought disorganization, } \\
\text { perplexity or confusion, disturbance of affect and mood, } \\
\text { catatonia-like symptoms changing daily or even faster }\end{array}$ & $\begin{array}{l}\text { Delusions, hallucinations, disorganized speech, grossly disorganized } \\
\text { or catatonic behaviour }\end{array}$ \\
\hline Duration & $<3$ months & 1 day to $<1$ month with full return to premorbid functioning \\
\hline Associated stress & Not specified & Specify if with marked stressors or onset $\leq 4$ weeks postpartum \\
\hline Course specifies & $\begin{array}{l}\text { First episode or multiple episodes: currently symptomatic, } \\
\text { in partial or full remission, unspecified }\end{array}$ & $\begin{array}{l}\text { First episode or multiple episodes: currently symptomatic, in partial } \\
\text { or full remission, unspecified }\end{array}$ \\
\hline $\begin{array}{l}\text { Psychopathological } \\
\text { dimensions }\end{array}$ & $\begin{array}{l}\text { Positive, negative, depressive, manic, psychomotor, and } \\
\text { cognitive }\end{array}$ & $\begin{array}{l}\text { Delusion, hallucination, disorganized speech, abnormal } \\
\text { psychomotor behaviour, negative symptoms, depression, mania, } \\
\text { impaired cognition }\end{array}$ \\
\hline Exclusion & $\begin{array}{l}\text { Schizophrenia, delusional disorder, psychosis due to } \\
\text { medical conditions, substance or medication use }\end{array}$ & $\begin{array}{l}\text { Schizophreniform disorder, affective disorder, substance-induced } \\
\text { psychosis, psychosis due to medical conditions, psychotic disorder } \\
\text { NOS }\end{array}$ \\
\hline
\end{tabular}

ATPD, acute and transient psychotic disorder; BPD, brief psychotic disorder. ${ }^{1}$ Acute onset of psychotic symptoms that emerge without a prodrome and reach their maximal severity within 2 weeks [13].

mediate level of destructuration of consciousness between manic-depressive attacks and confusional-oneiroid states according to Ey [21] organo-dynamic theory, and more recently French psychiatrists formulated empirical criteria for it [22] under the influence of symptombased psychiatric classifications. The Classification Française des Troubles et Maladies (CFTEM R-2015) issued in 2015 [23] listed bouffée délirante and its variants polymorphe, imaginative, interprétative, and hallucinatoire in keeping with the mechanism of symptom formation and provided crosswalks with the ICD-10 ATPD category.

\section{Cycloid Psychoses}

The theory of "degeneration" offered a speculative basis to the so-called endogenous psychoses, and Kleist [4] coined the term zykloide Psychosen to designate "phasic illnesses which come and go autochthonously like manic depression, frequently in dual, contrasting phases of confused excitement and stupor, or hyperkinesis and akinesis, running their course and leaving behind no residual defects" (p. 300). Leonhard [5] added the anxiety-happiness psychosis, which resulted from the combination of anxiety psychosis and revelation psychosis. The cycloid psychoses therefore comprised anxiety-happiness psychosis, confusion psychosis, and motility psychosis, which involved selectively an impairment of affect, thinking, and psychomotor activity, and were distinct from bipolar disorder and schizophrenia.
In Anglophone psychiatry, Perris [24] challenged Leonhard's clinical subtypes and proposed the concept of cycloid psychotic disorder provided with operational criteria, which became the standard diagnostic approach to cycloid psychosis [25]. The reliability of Perris and Brockington's [25] operational diagnosis of cycloid psychosis is high [26], and their criteria were incorporated in ICD-10, though the concordance with ATPDs is incomplete $[26,27]$. Even less likely to overlap with ATPDs is bouffée délirante, as the French criteria proved more stringent [28].

Reactive (Psychogenic) Psychosis

Drawing on the methodological distinction between "explanation" and "understanding," Jaspers [6] described the concept of reactive psychosis encompassing clinical conditions with affective, confusional, and paranoid symptoms, which were meaningfully connected to the extent of a psychical trauma, semantic or symbolic role (i.e., defence, escape, and wish fulfilment), and/or content.

This concept was further developed in Scandinavian countries, where its meaning varied in relation to the role attributed either to mental trauma or constitutional vulnerability $[6,29]$, but its validity was hampered by followup studies pointing out high transition rates to schizophrenia and affective disorders [30]. In Continental (European) and British psychiatry, the diffusion of reactive
Castagnini/Berrios 
psychosis was hindered by strong opposition to the notion of psychogenesis and controversies about the differentiation between reactive and endogenous depression [31]. Moreover, Schneider's [2] distinction between reaction to lived experiences (abnormen seelischen Reaktionen) and psychosis contributed to causing the neglect of reactive psychosis, while current psychiatric classifications have resumed in semantic terms the mind-body dichotomy as short-lived psychotic disorders may be associated or not with stressful events $[8,9]$.

There is little evidence for conceptual continuity as the ATPD category embraces conditions that refer to different interpretative theories: bouffée délirante involves hereditary factors and hinges on the antinomy of acuteness of onset and polymorphic features versus a more uniform clinical pattern leading eventually to mental deterioration; the characteristic features of cycloid psychosis are bipolar symptomatology, recurrent course, and favourable outcome; and reactive psychosis is an inferential category based on the psychological notion of "reactivity," which has been re-defined in terms of stress vulnerability, life events, and sociocultural adversities [30]. These categories have long been used in different psychiatric traditions for clinical and therapeutic reasons and bear a precise meaning only when set in context, owing to changes in the concept of psychosis and causal models since the early twentieth century [16]. Kleist [4] and Leonhard's [5] concept of cycloid psychosis therefore does not mean the same as modern operational definitions, and this also applies to bouffée délirante and reactive psychosis. In consequence, research findings based on earlier nosological concepts are obsolete and unlikely to prove helpful in practical terms.

\section{Diagnostic Validity}

Validity is a concept not easy to work with when referring to mental disorders. The method commonly used to assess the validity of psychiatric categories was developed by Robins and Guze [32] and involves 5 phases: (1) clinical description; (2) laboratory studies (i.e., psychological tests, postmortem, and neuroradiology studies); (3) delimitation from other categories; (4) follow-up studies to determine course, outcome, and diagnostic stability; and (5) family studies. This approach was influential in the development of the research criteria known as Feighner's criteria [33], which resulted in the publication of the Research Diagnostic Criteria (RDC), a forerunner to DSMIII [34], and was later reviewed by Kendler [35] in 3 main groups of antecedent, concurrent, and prognostic validators.

Conceptual Issues in Acute Transient Psychoses
More recently, Andreasen [36] proposed a "second structural programme" complemented by powerful research techniques for studying mental disorders into their underlying mechanisms such as neuroimaging and molecular genetics, but research has not yet been completed for any psychiatric category. In view of this, the US National Institute of Mental Health funded the Research Domain Criteria (RDoC) programme to achieve a classification of mental disorders based mainly on neurobiological findings from 5 domains of functioning (i.e., negative valence systems, positive valence systems, cognitive systems, systems for social processes, and arousal - modulatory systems) [37].

With regard to short-lived psychotic disorders, it remains unclear whether techniques such as neuroimaging and molecular genetics are suitable for these conditions, since they are not associated with brain changes or genetic alterations $[10,11]$. It is also likely that research has been affected by changes in definition and diagnostic criteria for these conditions in successive versions of DSM and ICD classifications. For example, DSM-III "brief reactive psychosis" underwent significant revision in DSMIII-R and was replaced with BPD in DSM-IV, which may be associated or not with marked stressors or arise within 4 weeks postpartum [38]. The same happened with the ICD-8 category "other psychoses," which included "psychotic conditions attributable to a recent life experience" such as reactive depression, reactive excitation, reactive confusion, acute paranoid reaction, and psychogenic paranoid psychosis and was restricted to the "small group of psychotic conditions that are largely or entirely attributable to a recent life experience" in ICD-9 [30]. Both categories differ from ICD-10 ATPDs, where acute stress constitutes an optional diagnostic feature, and the temporal relationship with symptom onset is limited to 2 weeks [8].

Moreover, ATPDs and BPD have tended to be excluded from surveys of first-episode psychosis, particularly the latter category has seldom been regarded as a specific topic of investigation owing to the lack of distinctive clinical features and brief duration [10]. Undue emphasis is also given to comparison with operational definitions for high-risk states for psychosis, while close scrutiny between ATPDs and "brief, limited, intermittent psychotic symptoms" (BLIPS; "fleeting psychotic experiences that spontaneously resolved within 1 week") revealed that similarities are limited to the subtype with schizophrenialike symptoms, probably because both conditions are shorter than 1 month, prevalent in young males, and the FRS are common diagnostic features [39]. 


\section{Symptom Completeness and Specificity}

In the absence of known causal factors and neurobiological correlates, modern psychiatric classifications have focused on diagnostic reliability and adopted operational criteria, according to which symptom recognition and their synthesis into diagnosis are independent and successive events (i.e., whenever the criteria a, b, and c are satisfied, then d will have to be diagnosed) [40].

The ATPD category changed between ICD-10 and ICD-1 1 from being a composite class encompassing polymorphic, schizophrenic, and predominantly delusional subtypes to a small grouping characterized by acuteness of onset, polymorphic symptoms, and early remission. Since symptoms also play a role in diagnosis of different disorders $[8,13]$, the fleeting nature of this category is a fairly indistinctive stipulation, and a temporal cutoff of $<3$ months is mentioned in order to set it apart from other primary psychotic disorders. In addition, the differentiation between polymorphic ATPD and cases with acute schizophrenia-like symptoms is mainly based on FRS, though their recognition proves difficult in presence of perplexity, mood swings, and/or psychomotor agitation [41]. Similarly, arbitrary appears definition of acute onset by ICD-11 in terms of "psychotic symptoms that emerge without a prodrome and reach their maximal severity within 2 weeks" [13]. In DSM-5 [9], BPD is defined by very general symptoms and differentiated from more severe and longer-lasting psychotic disorders by temporal criteria in keeping with the schizophrenia spectrum model. This reveals more about the technicalities of psychiatric diagnostics rather than the illness itself and raises doubts about the completeness and specificity of symptoms [16].

Moreover, the polymorphic ATPD category exhibits distinctive epidemiological features, being more common in women with an age of onset in early to mid-30s, and greater diagnostic stability than the clinical subtypes with schizophrenia-like and predominantly delusional symptoms [42], but very few attempts have been made to examine the specificity of polymorphic symptoms. This is probably due to both practical and theoretical reasons, as it is not easy to identify these conditions owing to their rarity (cases with polymorphic symptoms are numerically fewer than those diagnosed with ICD-10 ATPDs), and poll data efficiently unless a stable diagnosis is used $[11,12,42]$. Since symptoms are not only polymorphic but also variable over time, it is unsurprising that clinicians can disagree over whether this category applies or not, as evidenced by the field trials conducted to test the reliability and clinical utility of the ICD-11 Clinical Descriptions and Diagnostic Guidelines, which failed to achieve established standards of reliability for it [43].

\section{Conclusions}

Little continuity exists between earlier nosological concepts and the diagnostic categories used to classify short-lived psychotic disorders in the current psychiatric classifications. It seems likely that shortcomings inherent to the categories themselves in terms of symptom completeness, specificity, and heterogeneity, in addition to changes in definition and diagnostic criteria in successive DSM and ICD versions, have affected empirical research, making it difficult to enhance the understanding of these conditions and achieve a closer concordance between the 2 classificatory systems.

\section{Conflict of Interest Statement}

The authors have no conflicts of interest to declare.

\section{Funding Sources}

This is a theoretical/historical paper, based on accumulated knowledge by authors and on their previous publications, and written in their own time. No funding was received.

\section{Author Contributions}

Both authors devised the study and wrote, revised, and approved the manuscript.

\footnotetext{
References

1 Kraepelin E. Psychiatrie. 5th ed. Leipzig: Barth; 1896.

2 Schneider K. Klinische Psychopathologie. 5th ed. Stuttgart: Thieme; 1959 (Clinical psychopathology. New York: Grune and Stratton; 1967).

3 Magnan V, Legrain M. Les dégénérés: état mentale et syndromes épisodiques. Paris: Rueff; 1885.

4 Kleist K. Über zykloide und epileptoide Psychosen und über die Frage der Degenerationspsychosen. Schw Arch Neurol Psychiatr. 1928;23:3-37.

5 Leonhard K. Aufteilung der endogenen Psychosen und ihre differenzierte Ätiologie. 8th ed. Stuttgart-New York: Thieme; 2003.
}

Castagnini/Berrios 
6 Jaspers K. Kausale und verständliche Zusammenhänge zwischen Schicksal und Psychose bei der Dementia praecox (Schizophrenie). Z Gesamte Neurol Psychiatr. 1913;14:159-263.

7 Wimmer A, editor. Psykogene sindssygdomsformer. St. Hans Hospital Jubilæumsskrift 1816-1916. København: Gad; 1916. p. 85216. (Psychogenic psychoses. Burnside: Adelaide Academic Press; 2003).

8 World Health Organization. The ICD-10 classification of mental and behavioural disorders: clinical descriptions and diagnostic guidelines. Geneva: World Health Organization; 1992.

9 American Psychiatric Association. Diagnostic and statistical manual of mental disorders (DSM-5). 5th ed. Washington, DC: American Psychiatric Association; 2013.

10 Castagnini AC, Fusar-Poli P. Diagnostic validity of ICD-10 acute and transient psychotic disorders and DSM-5 brief psychotic disorder. Eur Psychiatry. 2017;45:104-13.

11 Castagnini AC, Foldager L, Berrios GE. Acute polymorphic psychotic disorder: concepts, empirical findings and challenges for ICD-11. J Nerv Ment Dis. 2018;206:887-95.

12 Castagnini A, Berrios GE. Approach to refine ICD-11 acute and transient psychotic disorder (polymorphic psychotic disorder). Schizophr Res. 2019;212:239-40.

13 World Health Organization. ICD-11 classification of mental, behavioural and neurodevelopmental disorders. Genève: World Health Organization; 2018. Pre-published online: https://icd.who.int/browse11/l-m/en.

14 Stein DJ, Szatmari P, Gaebel W, Berk M, Vieta E, Maj M, et al. Mental, behavioral and neurodevelopmental disorders in the ICD-11: an international perspective on key changes and controversies. BMC Med. 2020;18:21.

15 Faiad Y, Khoury B, Daouk S, Maj M, Keeley J, Gureje O, et al. Frequency of use of the international classification of diseases ICD-10 diagnostic categories for mental and behavioural disorders across world regions. Epidemiol Psychiatr Sci. 2018;27:568-76.

16 Berrios GE. Conceptual problems in diagnosing schizophrenic disorders. In: Den Boer JA, Westenberg HGM, van Praag HM, editors.
Advances in the neurobiology of schizophrenia. New York: Wiley; 1995. p. 7-25.

17 Markova IS, Berrios GE. Research in psychiatry: concepts and conceptual analysis. Psychopathology. 2016;49:188-94.

18 Dupre E, Logre B. Les psychoses imaginatives aiguës. Ann Med Psychol. 1914;10:145-69.

19 Halberstadt G. Une question de doctrine psychiatrique: la psychose délirante dégénérative aiguë. Ann Med Psychol. 1922;12:100-18.

20 Serieux P, Capgras J. Les folies raisonnantes, le délire d'interpretation. Paris: Alcan; 1909.

21 Ey H. Les bouffées délirantes et les psychoses hallucinatoires aiguës. Étude n. 23. Ètudes psychiatriques. Paris: Desclée de Brouwer; 1954. Vol. 3; p. 203-324.

22 Pull MC, Pull CB, Pichot P. Des critères empiriques français per les psychoses. II: consensus des psychiatres français et definitions provisoires. Encéphale. 1987;13:53-7.

23 Garrabé J, Kammerer F. Classification Française des troubles mentaux R-2015. Rennes: Presses de l' École des Hautes Études en Santé Publique; 2015.

24 Perris C. A study of cycloid psychoses. Acta Psychiatr Scand Suppl. 1974;253:1-77.

25 Perris C, Brockington IF. Cycloid psychoses and their relation to the major psychoses. In: Perris C, Struwe G, Jansson B, editors. Biological psychiatry. Amsterdam: Elsevier; 1981. p. 447-50.

26 Peralta V, Cuesta MJ. Cycloid psychosis: a clinical and nosological study. Psychol Med. 2003;33:443-53.

27 Pillmann F, Haring A, Balzuweit S, Blöink R, Marneros A. Concordance of acute and transient psychoses and cycloid psychoses. Psychopathology. 2001;34:305-11.

28 Pillmann F, Haring A, Balzuweit S, Bloink R, Marneros A. Bouffée délirante and ICD-10 acute and transient psychoses: a comparative study. Aust N Z J Psychiatry. 2003;37:327-33.

29 Strömgren E. Psychogenic psychoses. In: Hirsch SR, Shepherd M, editors. Themes and variations in European psychiatry. Bristol: Wright; 1974. p. 102-25.

30 Castagnini AC. Wimmer's concept of psychogenic psychosis revisited. Hist Psychiatry. 2010;21:54-66.
31 Lewis A. Psychogenic: a word and its mutations. Psychol Med. 1972;2:209-15.

32 Robins E, Guze SB. Establishment of diagnostic validity in psychiatric illness: its application to schizophrenia. Am J Psychiatry. 1970; 126:983-7.

33 Feighner JP, Robins E, Guze SB, Woodruff RA, Winokur G, Munoz R. Diagnostic criteria for use in psychiatric research. Arch Gen Psychiatry. 1972;26:57-63.

34 Spitzer RL, Endicott J, Robins E. Clinical criteria for psychiatric diagnosis and DSM-III. Am J Psychiatry. 1975;132:1187-92.

35 Kendler KS. The nosologic validity of paranoia (simple delusional disorder). A review. Arch Gen Psychiatry. 1980;37:699-706.

36 Andreasen NC. Linking mind and brain in the study of mental illnesses: a project for a scientific psychopathology. Science. 1997;275: 1586-93.

37 Cuthbert BN, Insel TR. Toward the future of psychiatric diagnosis: the seven pillars of RDoC. BMC Med. 2013;11:126.

38 Ungvari GS, Mullen PE. Reactive psychoses revisited. Aust N Z J Psychiatry. 2000;34:45867.

39 Fusar-Poli P, Cappucciati M, De Micheli A, Rutigliano G, Bonoldi I, Tognin S, et al. Diagnostic and prognostic significance of brief limited intermittent psychotic symptoms (BLIPS) in subjects at ultra high risk. Schizophr Bull. 2017;43:48-56.

40 Berrios GE, Chen EYH. Recognising psychiatric symptoms. Relevance of the diagnostic process. Brit J Psychiatry. 1993;163:308-14.

41 Nordgaard J, Arnfred SM, Handest P, Parnas J. The diagnostic status of first-rank symptoms. Schizophr Bull. 2008;34:137-54.

42 Castagnini A, Foldager L. Epidemiology, course and outcome of acute and transient psychotic disorders: implications for ICD-11. Psychopathology. 2014;43:202-6.

43 Reed GM, Sharan P, Rebello TJ, Keeley JW, Medina-Mora ME, Gureje O, et al. The ICD11 developmental field trials study of reliability of diagnoses of high-burden mental disorders: results among adult patients in mental health settings of 13 countries. World Psychiatry. 2018;17:174-86.
Conceptual Issues in Acute Transient Psychoses
Psychopathology 2022;55:10-15 DOI: $10.1159 / 000520087$ 